Rahmath Ulla Baig

Shaik Dawood

Mohamed Mansour $\bowtie$

Tarik Tawfeek

https://doi.org/10.21278/TOF.44302

ISSN 1333-1124

eISSN 1849-1391

\title{
IDENTIFYING AND PRIORITISING FUTURE ROBOT CONTROL RESEARCH WITH MULTI-CRITERIA DECISION-MAKING
}

\begin{abstract}
Summary
The gap between researchers who carry out scientific exploration and practitioners who can make use of the research results is well known. In addition, while practitioners place a high value on research, they do not read many research papers. This paper attempts to define and prioritise future research in robotics using the analytical hierarchy process (AHP). Fifteen research alternatives and gaps, five performance criteria, eight industry types, and six production processes, investigated by both academics and practitioners, are filtered to six alternatives, four performance criteria, three industry types, and three production processes, respectively, based on the most important factors in decision-making. Subsequently, they are analysed by the Expert Choice software. This research aims at bridging the gap between academics and practitioners in robotics research and at conducting research that is relevant to industry. The results indicate that the research in multi-robot control ranked first with $26.8 \%$, followed by the research in safe control with $23.3 \%$ and the research in remote robot supervision with $19.0 \%$. The research in force control ranked fourth with $17.8 \%$, followed by the research in $3 \mathrm{D}$ vision and wireless communication with $8.4 \%$ and $6.4 \%$, respectively. Based on the results, the academics involved in robotics research should direct their effort to the research activities that received the highest priority in the AHP model.
\end{abstract}

Key words: $\quad$ future research in robotics, multi-criteria decision-making, analytical hierarchy process, qualitative analysis

\section{Introduction}

Today, much scientific research focuses on multi-robot control, safe control, force control, remote robot supervision, and wireless communication [1]. Prioritising research directions occurs in health care sciences and services [2], health policy and services, and economics, whereas there is no research focusing on future directions in the research into robotics control. According to the web of science core collection search [3], in the period 1905-2019, there have been 74,153 studies with a title identifying and prioritising future robot control research with multi-criteria decision-making (MCDM). 52\% of the research include proceeding papers and 42\% articles; $80 \%$ of them were published between 2008 and 2018 . $95 \%$ of the studies were conducted in 24 countries, where the USA, China, and Japan excelled and Iran and Turkey were the only Middle Eastern countries contributing to the robotics control research. 
The presence of a research plan in robotics control is valuable in guiding the efforts of researchers in applying the results of scientific research to industrial evolution. This area needs specialized research to be directed and carried out. This would allow specialized areas and their associated sub-disciplines, which determine the areas of scientific interest over time, to be prioritised compared to other area specializations. In this way, growing demands or emergency events occurring in society can be addressed. Prioritising research directions can assist in finding research topics for the next planning horizon, in directing financial support to areas of research preferred by community without neglecting other key scientific areas, in encouraging the formation of scientific research teams and centres, encouraging practical multidisciplinary engineering disciplines, and supporting scientific publishing. The prioritisation scheme is intended to rank a subset of alternatives with respect to a pre-defined set of criteria for complex decision-making problems.

We can consider the aspects of scientific research in the field of robotics control from several points of view, such as robot types, performance criteria, industry types, and production processes. Most research found in robotics control literature concentrates on one or two aspects by dealing with a single problem, such as the study by Xue et al. [4]. The research can have one or more objectives. In the case of multiple objectives, the researcher attempts to find a satisfactory trade-off between many conflicting criteria and achieve the best solution. The pairwise comparisons between alternatives in prioritising research directions can be based on objective and/or subjective attributes. Objective attributes are numerical, such as the cost of a robot. Subjective attributes are qualitative, such as the programming flexibility of a robot. Additionally, the pairwise comparisons are based on beneficial and/or non-beneficial attributes. Beneficial attributes are those whose higher values are desirable, such as load carrying capacity, programming flexibility, and speed. The non-beneficial attributes are those whose lower values are desirable, such as cost and repeatability. When prioritising one robotic control research direction over another, the decision maker seeks to maximize the performance measure through altering the attributes.

The robot plays a very important role in modern manufacturing industries [5], where it is a major asset in key manufacturing processes, such as painting and welding in the automotive industry [6], metal cutting and forming in the assembly industry [7], and labourrelated tasks in dangerous work areas. Moreover, in the space industry robots play an important role in imaging and investigating the characteristics of components in space research [8]. The heavy use of robots in industrial applications results from their stable quality and productivity level, cost minimization, and safety improvements in dangerous environments [9]. The selection of robots for a particular application and manufacturing environment is a difficult task for decision makers. Robot selection has become more complicated due to the increase in complexity, advanced features, and facilities of robots. The decision maker must identify and select the best-suited robot to achieve the desired output with respect to many criteria. MCDM is a complex decision-making tool involving both quantitative and qualitative factors. In recent years, several MCDM techniques and approaches have been utilised for choosing optimal probable options. Robotics research area alternatives can be defined by solving a certain problem related to functionality to optimize criteria for a certain application by specifying a manufacturing process type.

MCDM is a complex technique that defines criteria weights, the relationship between alternatives, and solution trade-offs through mathematical techniques [10]. The analytical hierarchy process (AHP) is an MCDM technique that enables the decision maker to choose one or more trade-off scenarios suitable to available resources. It has various applications from the construction industry [11], network selection and supply chain management [12] to healthcare services [13], material selection [14], risk assessment [15] and energy management. 
Robot selection for a given industrial application is a challenging and complicated procedure. In robot selection research, alternatives are clearly defined for finding solutions to certain problems, which refers to optimizing predefined criteria related to manufacturing area to choose the appropriate robots. Koulouriotis and Ketipi [16] provided a comprehensive integrated review and annotated taxonomy for robot evaluation and selection until 2014. Parameshwaran et al. [17] presented an integrated approach for optimal robot selection by considering both objective and subjective criteria by sequentially using the fuzzy Delphi/AHP/TOPSIS framework and VIKOR validation and the Brown-Gibson model. VIKOR is closest to the ideal solution. Sen et al. [18] explored the preference ranking organization method for enrichment evaluation as an efficient decision-making tool which provides the complete ranking order of all available alternatives. Sen et al. highlighted the application potential of preference ranking organization methods in relation to the robot selection problem when subjected to a set of quantitative evaluation data collected from the literature.

Simion et al. [19] applied the AHP method to select the most favourable industrial robot configuration for arc welding of a tracked mini-robot housing, which is used in military applications. The study highlighted the usefulness of the AHP in automated technological processes to facilitate and simplify the robot selection from a set of alternatives that carry out one or more tasks. Wang et al. [20] explored two key issues of robot evaluation and selection: assessment representation and robot rankings. Wang et al. developed a decision support model which utilised a cloud model and TODIM (a Portuguese acronym equivalent to interactive multi-criteria decision-making) for robot selection with hesitant linguistic information, which was used along with an entropy-based combination weighting technique to estimate the criteria weights. The TODIM approach is proposed for robot selection for automobile manufacturers, which validates the benefits and effectiveness of a robot through a comparative analysis. The results highlighted its unique advantages in a complex environment. Zhou et al. [21] proposed a VIKOR-based implementation method for integrating a fuzzy extended analytical hierarchy to select the mobile robot option with the smallest fuzzy utility value. The results highlight the sensitivity analysis, effectiveness, and robustness of the VIKOR extended approach.

Liu et al. [22] proposed a novel robot selection model by integrating the quality function development (QFD) theory and the qualitative flexible multiple criteria method under the interval-valued Pythagorean uncertain linguistical context. A modified qualitative flexible multiple criteria technique is utilised to generate the ranking order of alternative robots to determine the most suitable robot. Narayanamoorthy et al. [23] proposed using interval valued intuitionistic hesitant fuzzy entropy to determine the importance of criteria and the interval valued intuitionistic hesitant fuzzy VIKOR method to rank alternatives to perform complicated and hazardous tasks. The interval-valued intuitionistic hesitant fuzzy set includes a set of several possible interval-valued intuitionistic fuzzy membership and non-membership values to enhance the quality and efficiency of the work.

Kapoor and Tak [24] used the AHP method with selection criteria factors such as cost, velocity, repeatability, load capacity, stability, compliance, and accuracy. Chatterjee [25] used the AHP method with selection criteria factors such as load capacity, repeatability, maximum tip speed, memory capacity, and manipulator reach. Tansel [26] also used the AHP method with selection criteria factors such as pay load, repeatability, vertical reach, robot mass, axis motion range, and maximum axis speed. Abdel-Malek [27] used the decision support system method with selection criteria factors such as robot type (articulated robots, SCARA robots, etc.), degrees of freedom, pay load, horizontal reach, vertical reach, velocity, repeatability, and power supply. Bhangale et al. [28] utilised the optimal reciprocal collision avoidance and the technique for order of preference by similarity to ideal solution (TOPSIS) method with 
selection criteria such as load capacity, repeatability, maximum speed, type of drive, memory capacity, manipulator reach, and degree of freedom. Tao et al. [29] used the data envelopment analysis, AHP, TOPSIS, and axiomatic fuzzy set (AFS) theory selection criteria such as cost, load capacity, velocity, and repeatability error. Karsak [30] used QFD and the fuzzy linear regression method along with selection criteria such as load capacity, repeatability, vertical reach, horizontal reach, and warranty period.

Vahdani et al. [31] used fuzzy TOPSIS selection criteria such as purchase cost, load capacity, and positioning accuracy. Bhattacharya et al. [32] highlighted the QFD and AHP drive system, geometrical dexterity, path measuring system, robot size, robot material, robot weight, initial operating cost, pay load, accuracy, life-expectancy, robot velocity, programming flexibility, and total cost. Karsak et al.[33] used a fuzzy regression-based decision-making approach and selection criteria such as cost, velocity, repeatability, and load capacity. Chatterjee et al. [34] used the VIKOR and ELECTRE methods and selection criteria such as velocity, load capacity, cost, repeatability, vendor service quality, and programming flexibility. Kumar and Garg [35] proposed a distance-based approach, with selection criteria such as velocity, repeatability, load capacity, degree of freedom, stability, compliance, and accuracy. Koulouriotis and Ketipi [36] used fuzzy digraph and matrix methods and selection criteria such as man-machine interface, programming flexibility, repeatability error, purchase cost, and velocity.

In this study, after a rigorous review of articles addressing the application of MCDM to selection problems in different areas, such as robot selection, site allocation, knowledge management and supply chain design, the concomitant problems and opportunities that exist in implementing the AHP in prioritising future robot research are revealed. Based on the existing literature, it is evident that no studies integrate the MCDM technique in prioritising research directions, especially in the field of robotics control and in directing scientific research in general. Accordingly, this study seeks to motivate researchers to further explore state-of-the-art tools, including MCDM, and their applications in directing scientific research activities. The main objective of this research is to disseminate researcher approaches toward improving strategies, tools, and techniques of MCDM in the scientific research sector with a particular focus on its implementation.

The objective of this study is to prioritise research directions in the field of robotics control based on academics' and practitioners' opinions. This research adopted the general AHP approach introduced by Saaty [37]. The adopted hierarchy includes levels of goals, criteria, sub-criteria, and processes for alternative research topics. This study allows researchers in the robotics control domain to strengthen and focus their efforts for industry purposes and to reduce the inherent gap between academic research and industrial needs. It directs the budding robotic research efforts in the developing countries to the area of using robots in automation. Given the problem criteria, application field, processes, and robotics research alternatives, we hypothesized that researcher's and industrial expert's preferences are not equal for each research direction in the field of robotics. Since this problem is not examined in details in the literature, we focused on solving the prioritisation problem using an MCDM and presented results to direct the research efforts and optimize the resources available in a certain planning period to create a research plan. This type of problem treatment presents a new way of conducting robotics research by focusing and directing its efforts.

This paper is composed of four sections. In the second section, the adopted AHP model is illustrated. The third section applies the solution methodology to prioritise future research in robotics control based on the opinion and judgement of academic and industrial experts and the results are discussed. The fourth section provides conclusions and recommendations for future research. 


\section{Materials and methods}

In this study, the Saaty [37] procedure was implemented to design and develop an AHP model. The efficacy of the AHP model depends on the diversity and expertise opinion of the population, hence a diverse population from both the academic and the industrial sector was established, and a sample of people from both developed and developing countries were selected as illustrated in Table 1 , where $n_{a}$ and $n_{e}$ represent the number of academic and industrial expertise participants for a corresponding country, respectively. The number of participants is indicated in the ordered pair in parentheses. The total number of respondents was 629, however, there were 548 completed and validated questionnaires including 377 academics and 274 practitioners from 24 countries. The questionnaires were prepared online for respondents. The academics were selected based on their publication of robotic research articles in renowned journals, and industrial experts were contacted based on their involvement with pioneer robotics companies that have existed for over a decade. Participants were contacted, and their consent for the participation in the study was obtained via email. The responses are protected and will not be revealed unless a written consent from the respondent is acquired. Expert Choice [38] was used to conduct the AHP, and IBM SPSS V25.0.0 was used to calculate the geometric mean of the collected data.

Table 1 Sample characteristics

\begin{tabular}{cccccc}
\hline Country & $\left(n_{a}, n_{e}\right)$ & Country & $\left(n_{a}, n_{e}\right)$ & Country & $\left(n_{a}, n_{e}\right)$ \\
\hline $\begin{array}{c}\text { People's Republic } \\
\text { of China }\end{array}$ & $(12,13)$ & France & $(21,13)$ & Turkey & $(14,9)$ \\
USA & $(9,7)$ & Canada & $(24,19)$ & Australia & $(12,10)$ \\
Japan & $(28,23)$ & India & $(23,18)$ & Taiwan & $(18,14)$ \\
Germany & $(15,11)$ & Spain & $(18,10)$ & Switzerland & $(5,4)$ \\
Italy & $(12,7)$ & Iran & $(19,15)$ & Russia & $(10,8)$ \\
South Korea & $(11,8)$ & Singapore & $(20,14)$ & Mexico & $(18,13)$ \\
England & $(14,12)$ & Netherlands & $(15,10)$ & Sweden & $(12,8)$ \\
Brazil & $(20,13)$ & Portugal & $(13,4)$ & Malaysia & $(14,11)$ \\
\hline
\end{tabular}

The AHP was executed in Expert Choice, a widely-used MCDM software package. This process translated the answers of participants to the questions regarding the pairwise comparisons of level alternatives with the next highest corresponding level in the hierarchy. Five online 60-80-minute group sessions with a panel of experts were conducted to validate and refine the decision context, model content, and hierarchy. A questionnaire in the form of a comparison matrix was used to collect participant opinions. Fig. 1 shows the online questionnaire created to measure the relative pairwise comparison matrix of the main criteria with respect to the goal. Each participant decided on the relative pairwise comparison value of the main criteria with respect to the goal. It was required to circle a number per row using a scale value range from 1 to 9 . The " 1 " value indicates that the two alternatives have equal importance regarding the higher hierarchy level, while " 3 " indicates a moderate importance and "9" represents an extreme importance. Fig. 2 illustrates the relative pairwise comparison matrix of the main criteria with respect to cost, while Fig. 3 shows the relative pairwise comparison matrix of the main criteria with respect to automotive industry. 410 participants filled the pairwise comparison matrices, and the data were entered into the IBM Statistics $\mathrm{V}$ 25.0.0 software to calculate the geometric mean, which was then entered into Expert Choice. We used the ideal synthesis mode, which is designed to identify the single best alternative or the most important criterion [39]. 
A sensitivity analyses was performed to understand the impacts of objectives and weights on the results. Minimizing the cost, maximizing the tip speed/velocity, maximizing the robot repeatability, and maximizing the manipulator reach priorities were increased to $100 \%$, and the analysis was conducted in the distributive mode. The distributive mode produced results that evaluated alternatives or criteria proportionately. The consistency index was used to evaluate the transitivity of the weights [40]. An inconsistency percentage of less than $10 \%$ was accepted by the general AHP theory as defined by Saaty.

\begin{tabular}{|c|c|c|c|c|c|c|c|c|c|c|c|c|c|c|c|c|c|c|c|}
\hline \multirow{2}{*}{\multicolumn{2}{|c|}{$1=$ Equal }} & \multicolumn{18}{|c|}{ Circle one number per row below using the scale: } \\
\hline & & \multicolumn{5}{|c|}{3 = M oderate } & \multicolumn{5}{|c|}{5 = Strong } & \multicolumn{5}{|c|}{7 = Very strong } & \multicolumn{3}{|c|}{9 = Extreme } \\
\hline 1 & Cost & 9 & 8 & 7 & 6 & 5 & 4 & 3 & 2 & 1 & 2 & 3 & 4 & 5 & 6 & 7 & 8 & 9 & Maxim um tip speed/vel \\
\hline 2 & Cost & 9 & 8 & 7 & 6 & 5 & 4 & 3 & 2 & 1 & 2 & 3 & 4 & 5 & 6 & 7 & 8 & 9 & Repeatability \\
\hline 3 & Cost & 9 & 8 & 7 & 6 & 5 & 4 & 3 & 2 & 1 & 2 & 3 & 4 & 5 & 6 & 7 & 8 & 9 & Manipulator reach \\
\hline 4 & Maxim um tip speed/vel & 9 & 8 & 7 & 6 & 5 & 4 & 3 & 2 & 1 & 2 & 3 & 4 & 5 & 6 & 7 & 8 & 9 & Repeatability \\
\hline 5 & Maxim um tip speed/vel & 9 & 8 & 7 & 6 & 5 & 4 & 3 & 2 & 1 & 2 & 3 & 4 & 5 & 6 & 7 & 8 & 9 & Manipulator reach \\
\hline 6 & Repeatability & 9 & 8 & 7 & 6 & 5 & 4 & 3 & 2 & 1 & 2 & 3 & 4 & 5 & 6 & 7 & 8 & 9 & Manipulator reach \\
\hline
\end{tabular}

Fig. 1 Relative pairwise comparison matrix of main criteria with respect to goal.

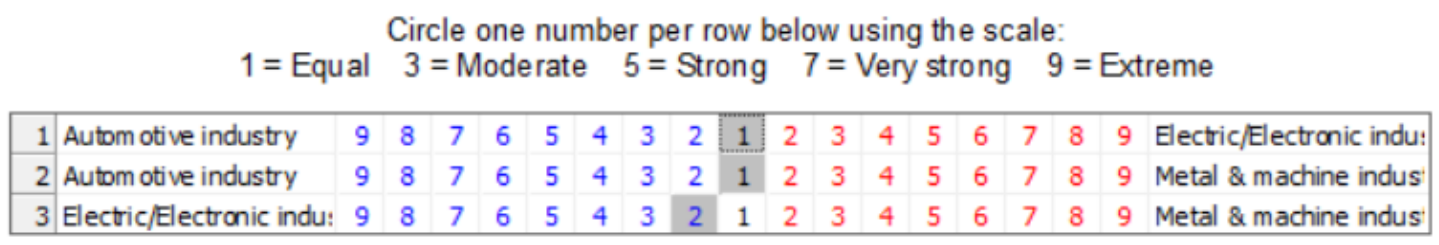

Fig. 2 Relative pairwise comparison matrix of main criteria with respect to cost.

Circle one number per row below using the scale:
= Equal $3=$ Moderate 5 = Strong $7=$ Very strong 9 = Extreme
\begin{tabular}{|l|l|l|l|l|l|l|l|l|l|l|l|l|l|l|l|l|l|l|l|}
\hline 1 & Welding & 9 & 8 & 6 & 5 & 4 & 3 & 2 & 1 & 2 & 3 & 4 & 5 & 6 & 7 & 8 & 9 & Assembly \\
\hline 2 & Welding & 9 & 8 & 7 & 6 & 5 & 4 & 3 & 2 & 1 & 2 & 3 & 4 & 5 & 6 & 7 & 8 & 9 & Material handling \\
\hline 3 & Assem bly & 9 & 8 & 7 & 6 & 5 & 4 & 3 & 2 & 1 & 2 & 3 & 4 & 5 & 6 & 7 & 8 & 9 & Material handling \\
\hline
\end{tabular}

Fig. 3 Relative pairwise comparison matrix of main criteria with respect to automotive industry.

\section{Results and discussion}

When using a descriptive analysis for the sample presented in Table 1 in terms of mean, standard deviation (SD), minimum value (Min), maximum value (Max), median (Med), and mode, it is noted that a) the observations for $n_{a}$ had a mean of 15.71, SD of 5.32, Min of 5, Max of 28, Med of 14.50, and mode of 12.00, and b) the observations for $n_{e}$ had a mean of 11.42, SD of 4.51, Min of 4.00, Max of 23, Med of 11.00, and mode of 13.00. The number of academic participants was higher than the number of industrial experts in all countries that participated in the questionnaire by an average value of 4.29 .

\subsection{Priorities of the main criteria with respect to goal}

As depicted in Table 2, repeatability has more weight than cost, speed, and robot reach. This result indicates that a robot's ability to return to the same position repeatedly is a vital indicator for robotic research as industrial robots have to repeatedly perform the same task millions of times [17]. Cost of the robot is ranked second, as cost is a deciding factor for many of the small and medium-sized enterprises in their decision whether to utilise a robot for their operations. It has been a constant endeavour of robot suppliers and researchers to create a cost-effective robot. The speed and reach of the robot falls further on the priority list; if a robot possesses high repeatability with cost effectiveness, then its speed should also be high to complete the task in less time and with a higher manipulator reach. 


\subsection{Priorities of the sub-criteria with respect to cost}

Robot selection based on cost is shown in Table 2. The electric and electronic industries, which have a market share of 32\% (according to the International Federation of Robotics Report), require cost-effective robots. As these industries require products which possess an economic advantage over their competitors, for the products to be delivered to customers, cost has a greater weight compared to other industries. In the electric and electronic industries, the key operation that robots perform is assembly of electronic components, as depicted by its weight of $65.9 \%$. Next in the cost criterion is the automotive industry where welding is the primary operation for which robots are purchased because of the need for high weld quality and consistency [41]. Assembly robots have revolutionized the automotive industry. They were the first robots which found acceptance in the industry and to this day they drive research as the complexity of products to be assembled is constantly increasing. The metal and machine industry, which is prioritised third in the selection of robots with reference to cost, requires welding operations to be automated using robots and has a weight of $68.3 \%$.

The scope of the robotic research in industry with cost as the main criterion includes multi-robot control, force control, safe control, remote robot supervision, 3D vision, and wireless communication. Welding robots play a critical role in the automotive and metal and machine industries; hence, the multi-robot control of welding robots is ranked high in the robotic research areas. Assembly robots are imperative in the electric and electronic industries and force control [42] in assembly lines has also great potential.

\subsection{Priorities of the sub-criteria with respect to maximum tip speed/velocity}

The speed of the robot is taken into consideration while selecting a robot in an industry as it affects productivity of a firm. The priority of speed is weighted third in the main criteria for robot selection. An increase in speed significantly affects the repeatability of the robot [43]; hence, in industries such as electric, electronic, and automotive where repeatability is a prime factor in efficient operation speed takes a back seat as depicted by the weights. Speed is distinctly prioritised in the metal and machine industries for welding operations $[44,45]$. It is also valued in assembly operations in the electric, electronic, and automotive industry. The ranking of robotic research areas with speed as a criterion is safe control (speed with safety), remote robot supervision, force control, wireless communication, multi-robot control, and 3D vision. The study of speed for remote robot supervision is vital as is indicated by the rankings; a supervising robot with high speed and safety requirements is a Herculean task for researchers.

\subsection{Priorities of the sub-criteria with respect to repeatability}

Repeatability of operations is of prime importance to automotive, electric and electronic industries compared to metal and machine industries as designated by the weights of the subcriteria. Welding an automobile requires producing precise welds, and welding robots are required to execute this repeatedly [45], which is depicted by the higher weight of $64.9 \%$. Assembly operations of electric and electronic components also require a high degree of repeatability as systems continue to mature with stringent requirements, which opens up areas of research for researchers in multi-robot control, safe control, and remote robot supervision. Repeatability in the metal and machine industries is essential with welding and the assembly of components compared to material handling. The scope of robotic research with repeatability as the criterion includes multi-robot control, safe control, remote robot supervision, force control, 3D vision, and wireless communication. 


\subsection{Priorities of the sub-criteria with respect to manipulator reach}

Manipulator reach is the least favoured criterion compared to repeatability, cost, and speed. Robot reach primarily refers to grasping the components in the metal and machine industry [46] and to reaching out to extreme points to perform welding operations. Correspondingly, in the automotive industry, the reach of the robot is of utmost importance for welding operations [47], whereas robot reach in the electronic and electrical industries is used for assembly operations requiring dexterity [48]. The hierarchy of robotic research areas regarding robot reach as the main criterion is multi robot control, force control, safe control, remote robot supervision, 3D vision, and wireless communication. Based on the AHP comparison of the overall weights, the hierarchy of robotics research areas in order of overall priority are: multi-robot control (0.268), safe control (0.233), remote robot supervision $(0.190)$, force control $(0.178), 3 \mathrm{D}$ vision, and wireless communication.

Table 2 Results of pairwise comparisons of the total weights of alternatives using Expert Choice

\begin{tabular}{|c|c|c|c|c|c|c|c|c|c|c|c|c|}
\hline \multirow[b]{2}{*}{ Criteria } & \multirow[b]{2}{*}{$\begin{array}{l}\text { Criterion } \\
\text { weight }\end{array}$} & \multirow[b]{2}{*}{$\begin{array}{l}\text { Sub- } \\
\text { criteria }\end{array}$} & \multirow[b]{2}{*}{$\begin{array}{c}\text { Local } \\
\text { sub- } \\
\text { criterion } \\
\text { weight }\end{array}$} & \multirow[b]{2}{*}{$\begin{array}{c}\text { Sub- } \\
\text { subcriterion }\end{array}$} & \multirow[b]{2}{*}{$\begin{array}{c}\text { Local } \\
\text { sub- } \\
\text { subcriterion } \\
\text { weight }\end{array}$} & \multirow[b]{2}{*}{$\begin{array}{c}\text { Global } \\
\text { sub- } \\
\text { subcriterion } \\
\text { weight }\end{array}$} & \multicolumn{6}{|c|}{ Robot research area alternatives } \\
\hline & & & & & & & $\begin{array}{l}\text { Multi- } \\
\text { robot } \\
\text { control } \\
(612)\end{array}$ & $\begin{array}{c}\text { Safe } \\
\text { control } \\
(56)\end{array}$ & $\begin{array}{l}\text { Force } \\
\text { control } \\
(495)\end{array}$ & $\begin{array}{l}3 \mathrm{D} \\
\text { vision } \\
(70)\end{array}$ & $\begin{array}{c}\text { Remote } \\
\text { robot } \\
\text { supervision } \\
(2)\end{array}$ & $\begin{array}{c}\text { Wireless } \\
\text { communication } \\
(66)\end{array}$ \\
\hline \multirow{9}{*}{$\overrightarrow{0}$} & \multirow{9}{*}{0.334} & \multirow{3}{*}{ Auto } & \multirow{3}{*}{0.327} & W & 0.570 & 0.062 & 0.021 & 0.018 & 0.008 & 0.006 & 0.006 & 0.004 \\
\hline & & & & A & 0.333 & 0.036 & 0.012 & 0.003 & 0.011 & 0.004 & 0.004 & 0.002 \\
\hline & & & & M & 0.097 & 0.011 & 0.002 & 0.003 & 0.002 & 0.001 & 0.001 & 0.001 \\
\hline & & \multirow{3}{*}{ Electr } & \multirow{3}{*}{0.413} & W & 0.185 & 0.026 & 0.009 & 0.005 & 0.004 & 0.003 & 0.003 & 0.001 \\
\hline & & & & A & 0.659 & 0.091 & 0.027 & 0.010 & 0.023 & 0.008 & 0.016 & 0.006 \\
\hline & & & & M & 0.156 & 0.022 & 0.001 & 0.006 & 0.002 & 0.003 & 0.007 & 0.003 \\
\hline & & \multirow{3}{*}{ Metam } & \multirow{3}{*}{0.260} & W & 0.683 & 0.059 & 0.023 & 0.010 & 0.009 & 0.005 & 0.010 & 0.003 \\
\hline & & & & A & 0.200 & 0.017 & 0.007 & 0.003 & 0.002 & 0.002 & 0.003 & 0.001 \\
\hline & & & & M & 0.117 & 0.010 & 0.001 & 0.003 & 0.003 & 0.001 & 0.002 & 0.001 \\
\hline \multirow{2}{*}{\multicolumn{2}{|c|}{$\begin{array}{l}\text { Cost total } \\
\text { Cost rank }\end{array}$}} & & 1.000 & & 3.000 & 0.334 & 0.103 & 0.062 & 0.063 & 0.033 & 0.052 & 0.022 \\
\hline & & & & & & & 1 & 3 & 2 & 5 & 4 & 6 \\
\hline \multirow{6}{*}{ 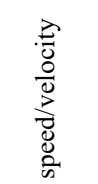 } & \multirow{9}{*}{0.136} & & & W & 0.218 & 0.010 & 0.001 & 0.004 & 0.002 & 0.001 & 0.001 & 0.002 \\
\hline & & Auto & 0.345 & A & 0.715 & 0.034 & 0.003 & 0.011 & 0.006 & 0.003 & 0.006 & 0.006 \\
\hline & & & & $\mathrm{M}$ & 0.067 & 0.003 & 0.000 & 0.001 & 0.001 & 0.000 & 0.001 & 0.000 \\
\hline & & & & W & 0.333 & 0.005 & 0.000 & 0.002 & 0.001 & 0.000 & 0.001 & 0.001 \\
\hline & & Electr & 0.109 & A & 0.570 & 0.008 & 0.000 & 0.003 & 0.001 & 0.001 & 0.002 & 0.001 \\
\hline & & & & M & 0.097 & 0.001 & 0.000 & 0.000 & 0.000 & 0.000 & 0.000 & 0.000 \\
\hline 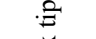 & & & & W & 0.574 & 0.043 & 0.004 & 0.015 & 0.007 & 0.003 & 0.011 & 0.002 \\
\hline త્త & & Metam & 0.547 & A & 0.361 & 0.027 & 0.003 & 0.009 & 0.005 & 0.002 & 0.007 & 0.001 \\
\hline & & & & M & 0.065 & 0.005 & 0.000 & 0.001 & 0.002 & 0.000 & 0.001 & 0.000 \\
\hline Max tip & speed/velo & city total & 1.000 & & 3.000 & 0.136 & 0.012 & 0.046 & 0.024 & 0.011 & 0.030 & 0.014 \\
\hline Max tip & speed/velo & city rank & & & & & 5 & 1 & 3 & 6 & 2 & 4 \\
\hline & & & & W & 0.649 & 0.121 & 0.051 & 0.018 & 0.013 & 0.008 & 0.024 & 0.006 \\
\hline & & Auto & 0.413 & A & 0.279 & 0.052 & 0.019 & 0.012 & 0.005 & 0.003 & 0.011 & 0.003 \\
\hline 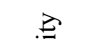 & & & & M & 0.072 & 0.013 & 0.001 & 0.005 & 0.002 & 0.001 & 0.003 & 0.001 \\
\hline 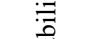 & & & & W & 0.279 & 0.041 & 0.004 & 0.014 & 0.006 & 0.004 & 0.011 & 0.002 \\
\hline 苞 & 0.451 & Electr & 0.327 & A & 0.649 & 0.096 & 0.010 & 0.033 & 0.014 & 0.009 & 0.025 & 0.006 \\
\hline ల్ర & & & & M & 0.072 & 0.011 & 0.004 & 0.002 & 0.001 & 0.001 & 0.002 & 0.000 \\
\hline$\tilde{2}$ & & & & W & 0.582 & 0.068 & 0.030 & 0.012 & 0.008 & 0.004 & 0.012 & 0.002 \\
\hline & & Metam & 0.260 & A & 0.348 & 0.041 & 0.006 & 0.003 & 0.020 & 0.002 & 0.008 & 0.001 \\
\hline & & & & $\mathrm{M}$ & 0.069 & 0.008 & 0.000 & 0.004 & 0.002 & 0.001 & 0.001 & 0.001 \\
\hline Repeatal & bility total & & 1.000 & & 2.999 & 0.451 & 0.125 & 0.103 & 0.070 & 0.033 & 0.097 & 0.023 \\
\hline Repeatal & bility rank & & & & & & 1 & 2 & 4 & 5 & 3 & 6 \\
\hline & & & & W & 0.701 & 0.020 & 0.008 & 0.003 & 0.003 & 0.002 & 0.002 & 0.001 \\
\hline$\div$ & & Auto & 0.352 & A & 0.240 & 0.007 & 0.003 & 0.001 & 0.002 & 0.000 & 0.001 & 0.000 \\
\hline ש & & & & M & 0.590 & 0.017 & 0.001 & 0.007 & 0.004 & 0.002 & 0.001 & 0.001 \\
\hline$\overline{0}$ & & & & W & 0.285 & 0.002 & 0.000 & 0.000 & 0.000 & 0.000 & 0.000 & 0.000 \\
\hline 疍 & 0.08 & Electr & 0.089 & A & 0.653 & 0.005 & 0.000 & 0.001 & 0.002 & 0.000 & 0.001 & 0.000 \\
\hline $\bar{\Xi}$ & & & & M & 0.062 & 0.000 & 0.000 & 0.000 & 0.000 & 0.000 & 0.000 & 0.000 \\
\hline$\overline{\bar{\Xi}}$ & & & & W & 0.649 & 0.029 & 0.013 & 0.007 & 0.003 & 0.002 & 0.002 & 0.001 \\
\hline$\Sigma$ & & Metam & 0.559 & A & 0.279 & 0.012 & 0.002 & 0.001 & 0.006 & 0.001 & 0.002 & 0.001 \\
\hline & & & & M & 0.072 & 0.003 & 0.000 & 0.001 & 0.000 & 0.001 & 0.000 & 0.000 \\
\hline Manipul & lator reach & total & 1.000 & & 3.531 & 0.095 & 0.028 & 0.022 & 0.022 & 0.008 & 0.010 & 0.005 \\
\hline Manipul & lator reach & rank & & & & & 1 & 3 & 2 & 5 & 4 & 6 \\
\hline Grand to & otal & & & & & & 0.268 & 0.233 & 0.178 & 0.084 & 0.190 & 0.064 \\
\hline Overall & priority/Ra & & & & & & 1 & 2 & 4 & 5 & 3 & 6 \\
\hline
\end{tabular}




\section{Conclusions}

This study investigated the criteria and indicators of the robotics research to concentrate the efforts of the research community to addressing industrial needs. Diverse multi-national experts from both industry and academia participated in the priority evaluation of the robotics research. The level of importance of the subcriteria is based on the pairwise comparisons conducted by experts. Based on the AHP comparison of the overall weights, the hierarchy of robotic research areas in descending order is: multi-robot control, safe control, remote robot supervision, force control, 3D vision, and wireless communication. This hierarchy indicates how research efforts should be channelled out to the development of effective industrial robotics.

The natural expansion of this research may involve exploring the applicability of using Fuzzy-AHP, TOPSIS, and other MCDM techniques for solving the research direction prioritisation problem. This research can also be extended to explore the relationship between the descriptive variable as a multivariate analysis and structure equation modelling for a cause-and-effect analysis of the factors affecting goals and objectives. Therefore, the advantages and disadvantages of the decision-making trial and evaluation laboratory compared to other methods remain unknown and can be further examined. Integrating the AHP with the QFD to prioritise research direction in the field of robotics control is a candidate research area related to the topic of this study. Availability of resources, planning horizons, and national/international directions can also be included in future research.

Acknowledgments: The authors are grateful to anonymous reviewers and editors for their comments and suggestions on this article.

\section{REFERENCES}

[1] Zolkiewski, S.; Pioskowik, D. Robot Control and Online Programming by Human Gestures Using a Kinect Motion Sensor, In: Rocha Á., Correia A., Tan F., Stroetmann K. (eds) New Perspectives in Information Systems and Technologies, Volume 1. Advances in Intelligent Systems and Computing, vol 275. Springer, Cham 2014, 593-604. https://doi.org/10.1007/978-3-319-05951-8_56

[2] Basu, A; Carlson, J.J.; Veenstra, D.L. A Framework for Prioritizing Research Investments in Precision Medicine, Value in Health 2015, 18 (7), A729-A729. https://doi.org/10.1016/j.jval.2015.09.2777

[3] Analytics Clarivate, "Web of Science," Clarivate Analytics, 2019.

[4] Xue, Y.X.; You, J.X.; Zhao, X.F.; Liu, H.C. An Integrated Linguistic MCDM Approach for Robot Evaluation and Selection with Incomplete Weight Information, International Journal of Production Research 2016, 54 (18), 5452-5467. https://doi.org/10.1080/00207543.2016.1146418

[5] Francesco, P.; Paolo, G.G. AURA: An Example of Collaborative Robot for Automotive and General Industry Applications, 27th International Conference on Flexible Automation and Intelligent Manufacturing, 2017, 338-345, Procedia Manufacturing M. Pellicciari and M. Peruzzini, eds.

[6] Pfeiffer, S. Robots, Industry 4.0 and Humans, or Why Assembly Work is more than Routine Work, Societies 2016, 6 (2), https://doi.org/10.3390/soc6020016

[7] Heydaryan, S.; Bedolla, J.S.; Belingardi, G. Safety Design and Development of a Human-Robot Collaboration Assembly Process in the Automotive Industry, Applied Sciences-Basel 2018, 8 (3), https://doi.org/10.3390/app8030344

[8] Yurdakul, M.; Ic Y.T. Application of Correlation Test to Criteria Selection for Multi Criteria Decision Making (MCDM) Models, International Journal of Advanced Manufacturing Technology 2009, 40 (3-4), 403-412. https://doi.org/10.1007/s00170-007-1324-1

[9] Cowan, L.S.; Walker, I.D. The Importance of Continuous and Discrete Elements in Continuum Robots, International Journal of Advanced Robotic Systems 2013, 10 https://doi.org/10.5772/55270 
[10] Giuseppe, M. Multiple Criteria Decision Analysis and Sustainable Development, International Series in Operations Research \& Management Science, International Series in Operations Research \& Management Science, 2005, 953-986, New York, NY: Springer-Verlag.

[11] Santoso, I.; Suripin; Darsono, S. Review of Criteria on Multi Criteria Decision Making (MCDM) Construction of Dams, International Journal of Geomate 2019, 16 (55), 184-194. https://doi.org/10.21660/2019.55.87673

[12] Banasik, A.; Bloemhof-Ruwaard, J. M.; Kanellopoulos, A.; Claassen, G.D.H.; van der Vorst, J.G.A.J. Multi-Criteria Decision Making Approaches for Green Supply Chains: A Review, Flexible Services and Manufacturing Journal 2018, 30 (3), 366-396. https://doi.org/10.1007/s10696-016-9263-5

[13] Mutlu, M.; Tuzkaya, G.; Sennaroglu, B. Multi-Criteria Decision Making Techniques for Healthcare Service Quality Evaluation: A Literature Review, Sigma Journal of Engineering and Natural SciencesSigma Muhendislik Ve Fen Bilimleri Dergisi 2017, 35 (3), 501-512.

[14] Noryani, M.; Sapuan, S.M.; Mastura, M.T. Multi-Criteria Decision-Making Tools for Material Selection of Natural Fibre Composites: A Review, Journal of Mechanical Engineering and Sciences 2018, 12 (1), 3330-3353. https://doi.org/10.15282/jmes.12.1.2018.5.0299

[15] Gul, M. A Review of Occupational Health and Safety Risk Assessment Approaches based on MultiCriteria Decision-Making Methods and their Fuzzy Versions, Human and Ecological Risk Assessment 2018, 24 (7), 1723-1760. https://doi.org/10.1080/10807039.2018.1424531

[16] Koulouriotis, D.E.; Ketipi, M.K. Robot Evaluation and Selection Part A: An Integrated Review and Annotated Taxonomy, International Journal of Advanced Manufacturing Technology 2014, 71 (5-8), 1371-1394. https://doi.org/10.1007/s00170-013-5525-5

[17] Parameshwaran, R.; Kumar, S.P.; Saravanakumar, K. An Integrated Fuzzy MCDM Based Approach for Robot Selection Considering Objective and Subjective Criteria, Applied Soft Computing 2015, 26 31-41. https://doi.org/10.1016/j.asoc.2014.09.025

[18] Sen, D.K.; Datta, S.; Patel, S.K.; Mahapatra, S.S. Multi-Criteria Decision Making towards Selection of Industrial Robot Exploration of PROMETHEE II Method, Benchmarking-an International Journal 2015, 22 (3), 465-487. https://doi.org/10.1108/bij-05-2014-0046

[19] Simion, M.; Socaciu, L.; Giurgiu, O.; Petrisor, S.M. The Selection of Industrial Robots for Military Industry using AHP Method: A Case Study, Acta Technica Napocensis Series-Applied Mathematics Mechanics and Engineering 2018, 61 (2), 231-240.

[20] Wang, J. J.; Miao, Z.H.; Cui, F.B.; Liu, H.C. Robot Evaluation and Selection with Entropy-Based Combination Weighting and Cloud TODIM Approach, Entropy 2018, 20 (5), 19. https://doi.org/10.3390/e20050349

[21] Zhou, F.L.; Wang, X.; Goh, M. Fuzzy Extended VIKOR-Based Mobile Robot Selection Model for Hospital Pharmacy, International Journal of Advanced Robotic Systems 2018, 15 (4), 11. https://doi.org/10.1177/1729881418787315

[22] Liu, H.C.; Quan, M.Y.; Shi, H.; Guo, C. An Integrated MCDM Method for Robot Selection under Interval-Valued Pythagorean Uncertain Linguistic Environment, International Journal of Intelligent Systems 2019, 34 (2), 188-214. https://doi.org/10.1002/int.22047

[23] Narayanamoorthy S.; Geetha S.; Rakkiyappan R.; Joo Y.H. Interval-Valued Intuitionistic Hesitant Fuzzy Entropy Based VIKOR Method for Industrial Robots Selection, Expert Systems with Applications 2019, 121, 28-37. https://doi.org/10.1016/j.eswa.2018.12.015

[24] Vikas, K.; Shyam Singh, T. Fuzzy Application to the Analytic Hierarchy Process for Robot Selection, Fuzzy Optimization Decision Making 2005, 4 (3), 209-234. https://doi.org/10.1007/s10700-005-1890-3

[25] Chatterjee, P.; Athawale, V.M.; Chakraborty, S. Selection of Industrial Robots using Compromise Ranking and Outranking Methods, J Robot. Comput.-Integr. Manuf 2010, 26 (5), 483-489. https://doi.org/10.1016/j.rcim.2010.03.007

[26] Tansel, Y.; Yurdakul, M.; Dengiz, B. Development of A Decision Support System for Robot Selection, J Robot. Comput.-Integr. Manuf 2013, 29 (4), 142-157. https://doi.org/10.1016/j.rcim.2012.11.008

[27] Abdel-Malek, L.; Resare, L.J. Algorithm Based Decision Support System for the Concerted Selection of Equipment in Machining/Assembly Cells, International Journal of Production Research 2000, 38 (2), 323-339. https://doi.org/10.1080/002075400189437 
[28] Bhangale, P P.; Agrawal, V.P.; Saha, S.K. Attribute Based Specification, Comparison and Selection of a Robot, Mechanism and Machine Theory 2004, 39 (12), 1345-1366. https://doi.org/10.1016/j.mechmachtheory.2004.05.020

[29] Tao, L.L.; Chen, Y.; Liu, X.D.; Wang, X. An Integrated Multiple Criteria Decision Making Model Applying Axiomatic Fuzzy Set Theory, Applied Mathematical Modelling 2012, 36 (10), 5046-5058. https://doi.org/10.1016/j.apm.2011.12.042

[30] Karsak, E.E. Robot Selection using an Integrated Approach based on Quality Function Deployment and Fuzzy Regression, International Journal of Production Research 2008, 46 (3), 723-738. https://doi.org/10.1080/00207540600919571

[31] Vahdani, B.; Tavakkoli-Moghaddam, R.; Mousavi, S.M.; Ghodratnama, A. Soft Computing Based on New Interval-Valued Fuzzy Modified Multi-Criteria Decision-Making Method, Applied Soft Computing 2013, 13 (1), 165-172. https://doi.org/10.1016/j.asoc.2012.08.020

[32] Bhattacharya, A.; Sarkar, B.; Mukherjee, S. K. Integrating AHP with QFD for Robot Selection under Requirement Perspective, International Journal of Production Research 2005, 43 (17), 3671-3685. https://doi.org/10.1080/00207540500137217

[33] Karsak, E.E.; Sener, Z.; Dursun, M. Robot Selection using a Fuzzy Regression-Based Decision-Making Approach, International Journal of Production Research 2012, 50 (23), 6826-6834. https://doi.org/10.1080/00207543.2011.627886

[34] Chatterjee, P.; Athawale, V.M.; Chakraborty, S. Selection of Industrial Robots using Compromise Ranking and Outranking Methods, Robotics and Computer-Integrated Manufacturing 2010, 26 (5), 483 489. https://doi.org/10.1016/j.rcim.2010.03.007

[35] Kumar, R.; Garg, R.K. Optimal Selection of Robots by using Distance Based Approach Method, Robotics and Computer-Integrated Manufacturing 2010, 26 (5), 500-506. https://doi.org/10.1016/j.rcim.2010.03.012

[36] Koulouriotis, D.E.; Ketipi, M.K. A Fuzzy Digraph Method for Robot Evaluation and Selection, Expert Systems with Applications 2011, 38 (9), 11901-11910. https://doi.org/10.1016/j.eswa.2011.03.082

[37] Saaty; Thomas, L., Fundamentals of the Analytic Hierarchy Process: Springer Netherlands, 2001.

[38] Garson; David, G., "Expert Choice," 2, Expert Choice, Inc., 1997, 221-224.

[39] Forman, E.H.; Gass, S.I. The Analytic Hierarchy Process - An exposition, Operations Research 2001, 49 (4), 469-486. https://doi.org/10.1287/opre.49.4.469.11231

[40] Dolan, J.G. Multi-Criteria Clinical Decision Support A Primer on the Use of Multiple-Criteria DecisionMaking Methods to Promote Evidence-Based, Patient-Centered Healthcare, Patient-Patient Centered Outcomes Research 2010, 3 (4), 229-248. https://doi.org/10.2165/11539470-000000000-00000

[41] Siciliano, B.; Sciavicco, L.; Villani, L.; Oriolo, G., Robotics: Modelling, Planning and Control: Springer Publishing Company, Incorporated, 2008.

[42] Brogardh, T. Present and Future Robot Control Development - An Industrial Perspective, Annual Reviews in Control 2007, 31 (1), 69-79. https://doi.org/10.1016/j.arcontrol.2007.01.002

[43] Offodile, O.F.; Ugwu, K. Evaluating the Effect of Speed and Payload on Robot Repeatability, Robotics and Computer-Integrated Manufacturing 1991, 8 (1), 27-33.

https://doi.org/10.1016/0736-5845(91)90004-c

[44] Limbu, D.K.; Tan, Y.K.; Wong, C.Y.; Jiang, R.D.; Wu, H.X.; Liu, L.Y.; Kah, E.H.; Yu, X.G.; Liu, D.; Liu, H.Z. Experiences with a Barista Robot, FusionBot, Progress in Robotics, Proceedings, Communications in Computer and Information Science J. H. Kim, S. S. Ge, P. Vadakkepat, N. Jesse, A. AlManum, S. Puthusserypady, U. Ruckert, J. Sitte, U. Witkowski, R. Nakatsu, T. Braunl, J. Baltes, J. Anderson, C. C. Wong, I. Verner and D. Ahlgren, eds. 2009, 140-151

[45] Kah, P.; Shrestha, M.; Hiltunen, E.; Martikainen, J. Robotic Arc Welding Sensors and Programming in Industrial Applications, International Journal of Mechanical and Materials Engineering 2015, 10 (1), https://doi.org/10.1186/s40712-015-0042-y

[46] Chu, T.C.; Lin, Y.C. A Fuzzy TOPSIS Method for Robot Selection, International Journal of Advanced Manufacturing Technology 2003, 21 (4), 284-290. https://doi.org/10.1007/s001700300033

[47] Bolmsjo, G.; Olsson, M.; Cederberg P. Robotic Arc welding-Trends and Developments for Higher Autonomy, Industrial Robot 2002, 29 (2), 98-104. https://doi.org/10.1108/01439910210419088 
R. Baig, S. Dawood,

M. Mansour, T. Tawfeek
Identifying and Prioritising Future Robot Control Research with Multi-Criteria Decision-Making

[48] Lopez-Juarez, I.; Corona-Castuera, J.; Pena-Cabrera, M.; Ordaz-Hernandez, K. On the Design of Intelligent Robotic Agents for Assembly, Information Sciences 2005, 171 (4), 377-402. https://doi.org/10.1016/j.ins.2004.09.011

Submitted: $\quad 21.12 .2019$

Rahmath Ulla Baig ${ }^{1}$

Accepted: $\quad 28.02 .2020$

Shaik Dawood ${ }^{2}$

${ }_{1,2,3}$ Industrial Engineering Department, College of Engineering, King Khalid University, Abha, Saudi Arabia

Mohamed Mansour ${ }^{* 3,4}$

${ }^{4}$ Industrial Engineering Department, College of Engineering, Zagazig University, Zagazig, EL-Sharkia, Egypt

*Corresponding author

e-mail: momansor@kku.edu.sa

phone: +966-54-575-0250

Tarik Tawfeek ${ }^{5}$

${ }^{5}$ Mechanical Engineering Department, College of Engineering, Benha university, Shoubra, Egypt 